\title{
Short adult height increases the risk of end-stage renal disease in type 2 diabetes
}

\author{
Yu Ah Hong ${ }^{1}$, Kyung-Do Han², Jae-Seung Yun ${ }^{3}$, Eun Sil Koh', Seung-Hyun $\mathrm{Ko}^{3}$ and Sungjin Chung(1) \\ 'Division of Nephrology, Department of Internal Medicine, College of Medicine, The Catholic University of Korea, Seoul, Republic of Korea \\ ${ }^{2}$ Department of Statistics and Actuarial Science, Soongsil University, Seoul, Republic of Korea \\ ${ }^{3}$ Division of Endocrinology and Metabolism, Department of Internal Medicine, College of Medicine, The Catholic University of Korea, Seoul, \\ Republic of Korea
}

Correspondence should be addressed to S-H Ko or S Chung: kosh@catholic.ac.kr or chungs@catholic.ac.kr

\begin{abstract}
Objective: Although short adult height has been associated with an increasing variety of diseases and all-cause death, no reliable data exist on the association between adult height and end-stage renal disease (ESRD) in diabetic patients. We investigated the relationship between short adult height, development of ESRD, and mortality in type 2 diabetes mellitus (DM).

Methods: This nationwide population-based cohort study analyzed clinical data from a total of 2,621,907 subjects aged $\geq 30$ years with type 2 DM between January 1, 2009 and December 31, 2012, using the National Health Insurance Database in Korea.

Results: During a 6.9-year follow-up period, 220,457 subjects (8.4\%) died, and 28,704 subjects $(1.1 \%)$ started dialysis. Short adult height significantly increased the incidence of ESRD and all-cause mortality in the overall cohort analysis. In multivariable Cox models, hazard ratios (HR) for the development of ESRD comparing the highest and lowest quartiles of adult height were 0.86 (95\% Cl 0.83-0.89). All-cause mortality also decreased with the highest height compared to patients with the lowest height, after fully adjusting for confounding variables ( $\mathrm{HR} 0.79,95 \% \mathrm{Cl} 0.78-0.81$ ). Adult height had an inverse relationship to newly diagnosed ESRD (male: HR $0.86,95 \% \mathrm{Cl} 0.83-0.90$, female: HR 0.84 , $95 \% \mathrm{Cl} 0.79-0.90$ ) and all-cause mortality (male: HR 0.81, 95\% Cl 0.79-0.82, female: HR $0.80,95 \% \mathrm{Cl} 0.78-0.82)$.

Conclusions: Short adult height is strongly associated with the increased risk of ESRD development and all-cause mortality in type 2 DM.
\end{abstract}

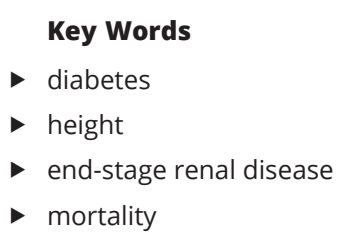

Endocrine Connections (2020) 9, 912-921

\section{Introduction}

Diabetic nephropathy is a major microvascular complication of type 2 diabetes mellitus (DM), and in many countries of the world, it is the major cause of endstage renal disease (ESRD) $(1,2,3)$. Identification of highrisk patients with type $2 \mathrm{DM}$ who would benefit from intensive treatment and follow-up is very important to prevent or delay the development of ESRD. Advanced age, duration of diabetes, poor glycemic control, hypertension, dyslipidemia, obesity, ethnicity, and socioeconomic factors were established risk factors for DM-related ESRD (4).
Despite efforts to control for these risk factors, the proportion of incident dialysis in diabetic patients is continuously rising. Further investigation is needed for risk stratification of the development of ESRD in DM.

Adult height is the cumulative outcome of nutritional environment and genetic factors during the early growth period. Short height may be a marker of inadequate fetal growth and subsequent impaired growth in early childhood, and factors that are related to certain metabolic diseases in adulthood (5). Several epidemiologic studies
This work is licensed under a Creative Commons Attribution-NonCommercial 4.0 International License. ded from Bioscientifica.com at ๑4/26/2023 10:20:0๑AM 
have reported that short adult height in the normal population is associated with adverse outcomes, including hypertension, hypercholesterolemia, microalbuminuria, impaired glucose tolerance, type $2 \mathrm{DM}$, ocular diseases, and cardiovascular diseases, such as myocardial infarction, ischemic heart disease, heart failure, and stroke $(6,7$, $8,9,10,11)$. Short adult height is also associated with proteinuria in both type 1 and type 2 DM $(12,13,14)$, but no reliable data could be found on the association between final adult height and the development of ESRD in diabetic patients. Therefore, we investigated whether short adult stature is an independent risk factor for the development of ESRD in patients with type 2 DM.

Using a population-based cohort of the National Health Insurance Database in Korea, this study aimed to examine whether the incidences of newly diagnosed ESRD and all-cause death were different with respect to adult height, and to determine whether short adult height is associated with the development of ESRD and survival in patients with type $2 \mathrm{DM}$.

\section{Subjects and methods}

\section{Data sources}

This was a nationwide retrospective observational study using the Korean National Health Insurance (NHI) Claims Database of the Health Insurance Review Agency between 2009 and 2017. The national health insurance system (NHIS) biennially provides regular health check-ups to all members in the Republic of Korea. The Korean NHIS program includes a computerized database covering all claims data, such as patient demographics, drug prescriptions, diagnostic disease codes (International Classification of Disease, 10th revision; ICD-10), insurer payment coverage, patient deductions, and claimed treatment details $(15,16)$. After the study protocol was approved by an official review committee, the NHIS database became available to the researchers, and data were provided in anonymous form. The Institutional Review Board of the Catholic University of Korea Yeouido St. Mary's Hospital approved the study protocol (SC19ZNDI0125).

A total of 2,706,223 subjects aged $\geq 20$ years with type 2 DM who underwent an initial baseline health checkup by the NHIS between 2009 and 2012 were recruited. A total of 34,747 subjects who were less than 30 years old were excluded because they were more likely to have type 1 DM. Patients with missing data $(n=40,638)$ and with a diagnosis of ESRD before the index year $(n=8941)$ were also excluded, to avoid the confounding effect of preexisting ESRD (Fig. 1). Because adult height is affected by age and sex, subjects were divided into quintiles depending on adult height for each age group of (20-39, $40-49,50-59,60-69$, and $\geq 70$ ) years and sex. The quintiles from ten different age and sex groups were merged into a single quintile. Supplementary Table 1 (see section on supplementary materials given at the end of this article) shows the reference values for each quintile according to age and sex groups.

\section{Data collection}

Data were analyzed for all participants at baseline, and included age, sex, height, weight, BMI, waist circumference, blood pressure (BP), fasting glucose, estimated glomerular filtration rate (eGFR), and triglyceride after an overnight fast. Quality control of laboratory tests was performed according to the South Korean Association of Laboratory Quality Control. The presence of hypertension, DM, hyperlipidemia, chronic kidney disease (CKD), and lifestyle behavior, such as physical activities, smoking, and alcohol consumption, were evaluated using standardized self-reporting questionnaires. Smoking status was classified as non-smoker or current smoker, and alcohol consumption was classified as non-drinker or heavy drinker ( $\geq 30 \mathrm{~g} /$ day), based on a question about the frequency of alcohol intake. CKD was defined as eGFR less than $60 \mathrm{~mL} / \mathrm{min} / 1.73 \mathrm{~m}^{2}$. Low-income level was defined as the lowest $25 \%$ of income earners.

\section{Definitions}

The diagnostic criteria of type $2 \mathrm{DM}$ in all participants were as follows: at least one claim per year under ICD-10 codes for type 2 DM (E11-E14), or fasting glucose level $\geq 126 \mathrm{mg} / \mathrm{dL}$. All participants visited outpatient or inpatient care, were diagnosed with type $2 \mathrm{DM}$, and accepted at least one prescription of anti-diabetic drugs. The primary endpoint was newly diagnosed ESRD or allcause mortality during the follow-up period. Detection of ESRD was defined as the combination of ICD-10 codes for renal replacement therapy (N18-19), and special medical aid codes for the performance of hemodialysis or peritoneal dialysis (hemodialysis: O7011-O7020 or V001; peritoneal dialysis: O7071-O7075 or V003). Patients with ESRD are registered as special medical aid beneficiaries, and all expenses for medical care provided to dialysis patients are reimbursed by the Korean Health Insurance Review and Assessment Service. Therefore, all ESRD 
Participants ( $\geq 20$ years old) who had undergone Korea

Health Examination between 2009 to 2012

$(n=23,452,862)$
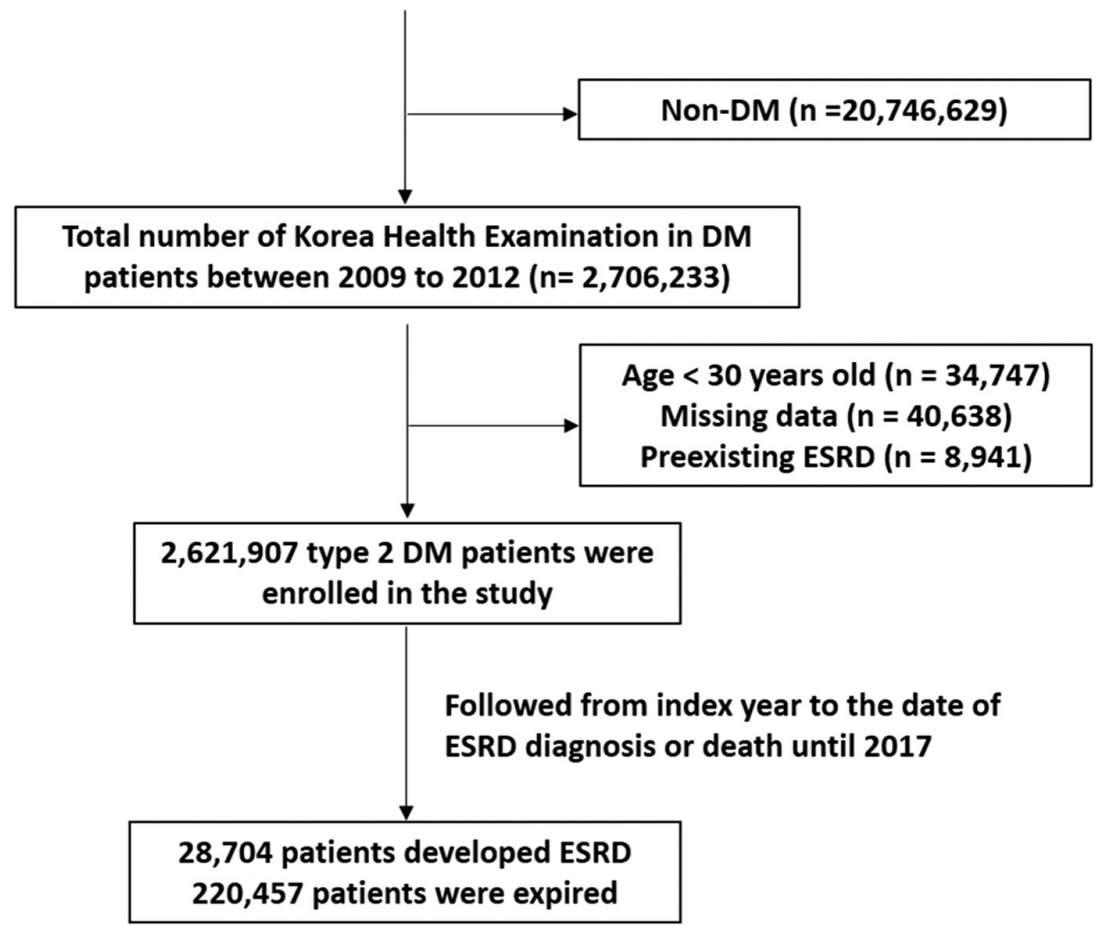

Figure

Flow chart of patient inclusion in the study.

patients in the whole population of South Korea could be recognized and analyzed. Subjects with acute kidney injury who simultaneously had both an acute renal failure code and a dialysis code, and subjects who had a continuous renal replacement therapy code or an acute peritoneal dialysis code, were excluded. Claims data were merged with national mortality data from the National Statistical Office for analysis.

\section{Statistical analyses}

Data for continuous variables are described as mean \pm S.D. or median value (interquartile range). Data for categorical variables are described as numbers and percentages. Incidence rates of ESRD and all-cause mortality were calculated as the number of incident cases divided by the entire follow-up period, and expressed per 1000 personyears. The strength of the association between adult stature and primary endpoint was assessed using the hazard ratio (HR) and 95\% CI calculated by Cox proportional-hazards regression analysis. Three models were model 1 adjusted for age, sex, and BMI; Model 2 adjusted for age, sex, BMI, smoking, alcohol intake, regular exercise, and low income; and Model 3 adjusted for age, sex, smoking, BMI, alcohol intake, regular exercise, low income, hyperlipidemia, hypertension, CKD, insulin use, oral hypoglycemic agents (OHA), and DM duration $>5$ years. All statistical analyses were performed using SAS version 9.4 software (SAS Institute, Cary, NC, USA). Statistical significance was set as $P$ value $<0.05$.

\section{Results}

\section{Baseline characteristics}

Table 1 shows baseline characteristics of the study population according to five groups of adult height levels. The study cohort consisted of 2,621,907 patients with type $2 \mathrm{DM}$ who were detected between 2009 and 2012, and followed until 2017. Mean age of the total population was $57.9 \pm 11.9$ years. Among all subjects, $1,575,271$ subjects $(60.1 \%)$ were male, $1,498,762(57.2 \%)$ had hypertension, 1,118,407 (42.7\%) had hyperlipidemia, and 291,461 (11.1\%) were diagnosed with CKD. Subjects in the lower quintiles of adult height were older, and more likely to be men. Weight circumference was lowest in the shorter groups, and adult BMI was also lower in the shorter groups. Lower quintiles of adult height had 


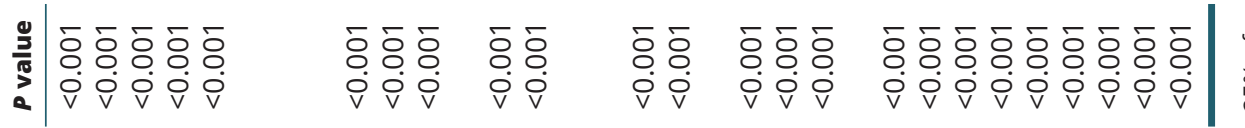

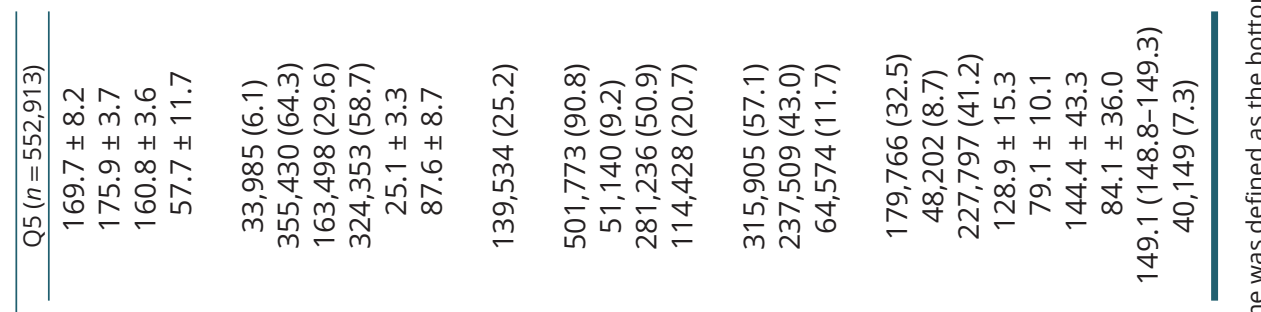
角 䒘苾

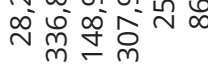

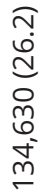

สุ

두으.

กิ

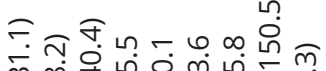

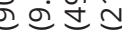

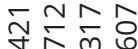

迎学导

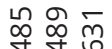

m

o $m+1++1+0$.

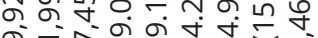

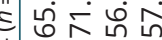

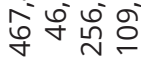

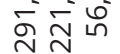

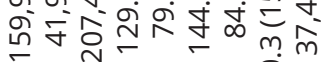

욤

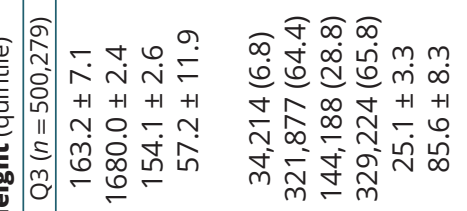

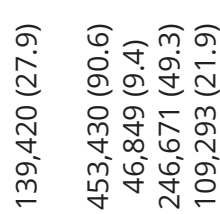

ช즈

மீं守宅

สุด

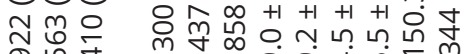

on

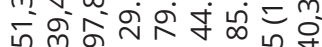

劳

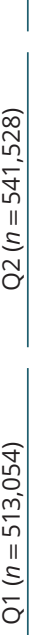

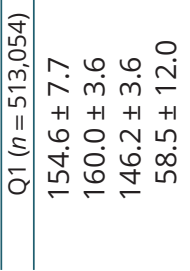

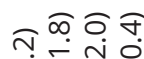

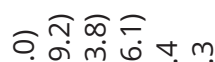

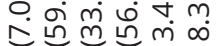

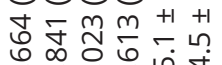

min

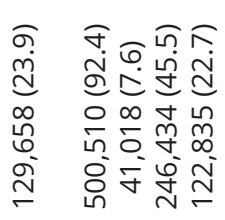

$\widehat{\partial} ช \widehat{\sigma}$

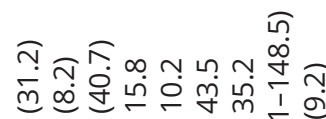

象桨导

동

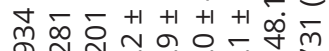

峲岗

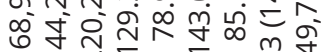

$\stackrel{\substack{m \\+}}{+}$

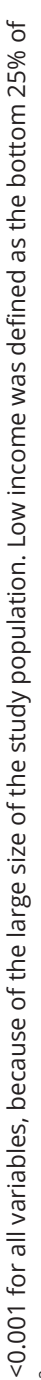


fewer heavy drinkers, fewer physical activities, and lower incomes. Systolic BP showed negative relationships with height. Shorter subjects had a lower proportion of diabetes duration longer than 5 years, and they used OHA and insulin injection less frequently. Shorter height was also associated with lower baseline levels of blood fasting glucose and triglyceride. Baseline levels of eGFR increased gradually as the heights of subjects decreased. Because of the large sample size, $P$ values for trend were $<0.001$ for all variables. During a mean follow-up period of 6.9 years, 28,704 (1.1\%) subjects were newly diagnosed with ESRD, and $220,457(8.4 \%)$ subjects died. The total number of deaths gradually increased from subjects with the highest to the lowest adult height.

\section{Association with height, incidence of end-stage renal disease, and all-cause mortality in type 2 diabetic subjects}

The relative risk of newly diagnosed ESRD and mortality was analyzed according to quintiles for adult height. Table 2 shows the results of the multivariable Cox regression analyses for the incidence of ESRD and allcause mortality. Overall, the incidence of ESRD and all-cause death in type $2 \mathrm{DM}$ were 1.59 and 12.14 per 1000 person-years, respectively. The incidence of ESRD was $1.66,1.61,1.59,1.51$, and 1.56, respectively, and the incidence of all-cause death was 14.90, 13.25, 11.63, 10.49, and 10.50, respectively, per 1000 person-years. All other groups had significantly lower incidence rates of ESRD, compared with those in the lowest quintile in type $2 \mathrm{DM}$.

The lowest quintile of adult height was used as a reference category of the HRs of ESRD and all-cause mortality, as shown in Table 2. Height was negatively associated with the incidence of ESRD in multivariable analysis. The HR for incident ESRD was 0.93 (95\% CI $0.9-0.97), \quad 0.90 \quad(95 \% \quad$ CI $\quad 0.87-0.94), \quad 0.86 \quad(95 \% \quad$ CI 0.83-0.89), and 0.86 (95\% CI 0.83-0.89) for the second, third, fourth, and fifth quintiles vs the first quintile of adult height, respectively, after adjusting for age, sex, BMI, smoking, alcohol intake, regular exercise, low income, hyperlipidemia, hypertension, CKD, insulin use, OHA, and DM duration $>5$ years $(P$ trend $<0.001$, Table 2 , model 3). Adult height was an independent predictor of newly diagnosed ESRD, even after full adjustment of the confounding factors.

An incrementally lower risk of all-cause death was also observed for the higher quintiles of adult height compared with the lowest quintile group in multivariable analysis. The tallest group had approximately $20 \%$ lower risk of allcause death than the shortest group, even after adjustment for age, sex, smoking, BMI, alcohol intake, regular exercise, low income, hyperlipidemia, hypertension, CKD, insulin use, OHA, and DM duration $>5$ years. The HR for allcause death was 0.88 (95\% CI 0.87-0.89), 0.84 (95\% CI $0.83-0.85$ ), 0.81 (95\% CI $0.80-0.82$ ), and 0.79 (95\% CI 0.78-0.81) for the second, third, fourth, and fifth quintiles vs the first quintile of adult height, respectively, even after full multivariable adjustment $(P$ trend $<0.001)$.

Table 2 Multivariate Cox regression analysis for end-stage renal disease and mortality by quintiles of height in diabetic subjects.

\begin{tabular}{|c|c|c|c|c|c|c|}
\hline & \multirow[b]{2}{*}{ Events/observed } & \multirow{2}{*}{$\begin{array}{l}\text { Follow-up duration } \\
\text { (person-years) }\end{array}$} & \multirow{2}{*}{$\begin{array}{c}\text { Incidence rate } \\
\text { (per } 1000 \text { person-years) }\end{array}$} & \multicolumn{3}{|c|}{ HR $(95 \% \mathrm{Cl})$} \\
\hline & & & & Model 1 & Model 2 & Model 3 \\
\hline \multicolumn{7}{|l|}{ ESRD } \\
\hline Q1 & $5856 / 513,054$ & $3,528,708$ & 1.66 & 1 (reference) & 1 (reference) & 1 (reference) \\
\hline Q2 & $6022 / 541,528$ & $3,739,612$ & 1.61 & $0.97(0.94-1.01)$ & 0.99 (0.95-1.02) & $0.93(0.9-0.97)$ \\
\hline Q3 & $5496 / 500,279$ & $3,455,874$ & 1.59 & $0.97(0.94-1.01)$ & 1.00 (0.96-1.03) & $0.90(0.87-0.94)$ \\
\hline Q4 & $5371 / 514,133$ & $3,558,167$ & 1.51 & $0.95(0.92-0.99)$ & $0.98(0.94-1.02)$ & $0.86(0.83-0.89)$ \\
\hline \multirow[t]{2}{*}{ Q5 } & $5959 / 552,913$ & $3,809,028$ & 1.56 & $0.98(0.94-1.01)$ & $1.01(0.98-1.05)$ & $0.86(0.83-0.89)$ \\
\hline & $P$ trend & & & 0.085 & 0.691 & $<0.001$ \\
\hline \multicolumn{7}{|c|}{ All-cause mortality } \\
\hline Q1 & $52,768 / 513,054$ & $3,542,352$ & 14.90 & 1 (reference) & 1 (reference) & 1 (reference) \\
\hline Q2 & $49,731 / 541,528$ & $3,753,381$ & 13.25 & $0.88(0.87-0.89)$ & $0.89(0.88-0.90)$ & $0.88(0.87-0.89)$ \\
\hline Q3 & $40,344 / 500,279$ & $3,468,864$ & 11.63 & $0.84(0.83-0.85)$ & $0.86(0.84-0.87)$ & $0.84(0.83-0.85)$ \\
\hline Q4 & $37,465 / 514,133$ & $3,570,716$ & 10.49 & $0.80(0.79-0.82)$ & $0.83(0.82-0.84)$ & $0.81(0.80-0.82)$ \\
\hline \multirow[t]{2}{*}{ Q5 } & $40,149 / 552,913$ & $3,822,972$ & 10.50 & $0.79(0.78-0.80)$ & $0.82(0.81-0.83)$ & $0.79(0.78-0.81)$ \\
\hline & $P$ trend & & & $<0.001$ & $<0.001$ & $<0.001$ \\
\hline
\end{tabular}

Model 1: adjusted for age, sex, BMI; Model 2: adjusted for age, sex, BMI, smoking, alcohol intake, regular exercise, and low income; Model 3: adjusted for age, sex, BMI, smoking, alcohol intake, regular exercise, low income, hyperlipidemia, hypertension, CKD, insulin use, OHA, and DM duration >5 years. CKD, chronic kidney disease; DM, diabetes mellitus; ESRD, end-stage renal disease; HR, hazard ratio; HTN, hypertension; OHA, oral hypoglycemia agents; Q, quintile.

https://ec.bioscientifica.com https://doi.org/10.1530/EC-20-0319 (c) 2020 The authors Published by Bioscientifica Ltd

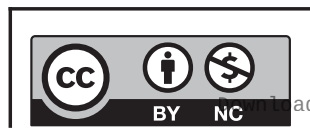

This work is licensed under a Creative Commons Attribution-NonCommercial 4.0 International License. ded from Bioscientifica.com at 04/26/2023 10:20:0๑AM via free access 


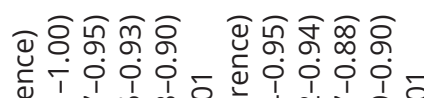

w

过

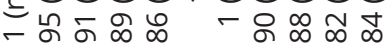

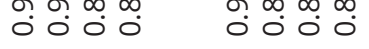

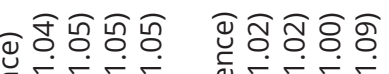

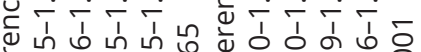

๘

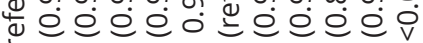

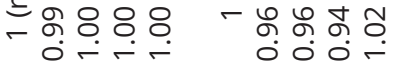

氚

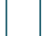

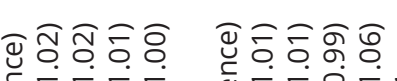

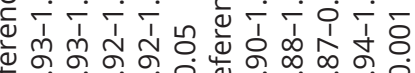

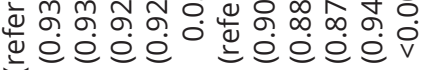

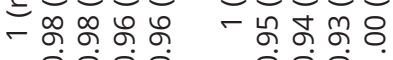

$\circ 000$

००००-

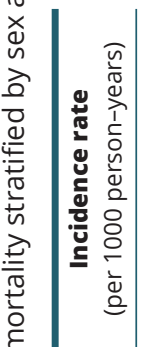

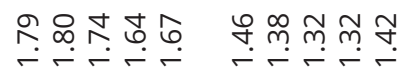

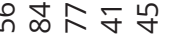

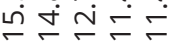

윰ㄴㅁㄴㅇㅠ

mं

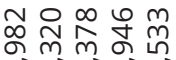

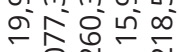

inini

녹ํำ ิำ

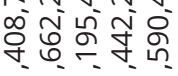

安

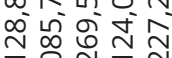

inivin

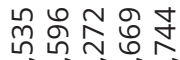

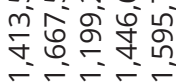

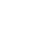

\begin{abstract}
iñ
\end{abstract}
ติ

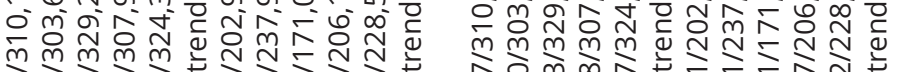

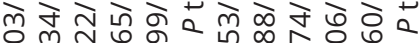

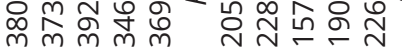

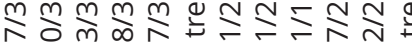

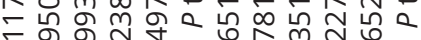

mं

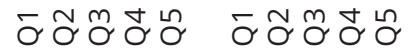

趉

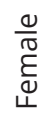

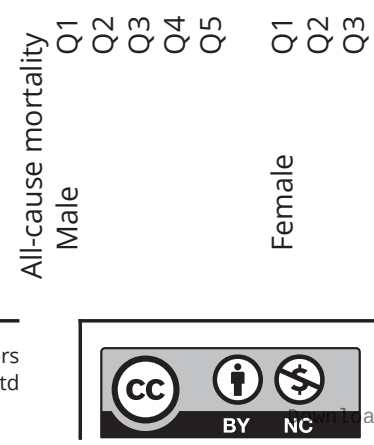

This work is licensed under a Creative Commons Attribution-NonCommercial 4.0 International License. 
Association with height stratified by sex and incidence of end-stage renal disease and all-cause mortality in type 2 diabetic subjects

The HR for adult height was stratified by sex in multivariable-adjusted models (Table 3). A similar pattern was found in the association between height, risk of ERSD, and death in subjects classified according to sex. Diabetic patients with tall stature had lower incidences of ESRD and all-cause death, after adjusting for age, sex, BMI, smoking, alcohol intake, regular exercise, low income, hyperlipidemia, hypertension, CKD, insulin use, OHA, and DM duration $>5$ years in both males and females. The HRs of ESRD for the second, third, fourth, and fifth quintiles vs the first quintile of adult height decreased to 0.95 (95\% CI 0.91-1.00), 0.91 (95\% CI 0.87-0.95), 0.89 (95\% CI 0.85-0.93), and 0.86 (95\% CI $0.83-0.90)$, respectively, for males $(P$ trend $<0.001)$; and to 0.90 (95\% CI $0.84-0.95), 0.88$ (95\% CI 0.82-0.94), 0.82 (95\% CI 0.77-0.88), and 0.84 (95\% CI 0.79-0.90), respectively, for females $(P$ trend $<0.001)$. The HRs of all-cause death for the second, third, fourth, and fifth quintiles vs the first quintile of adult height decreased to 0.90 (95\% CI $0.88-0.91$ ), 0.85 (95\% CI $0.84-0.87$ ), 0.83 (95\% CI $0.82-0.85$ ), and 0.81 (95\% CI $0.79-0.82)$ for males $(P$ trend $<0.001)$, respectively; and to $0.86(95 \% \mathrm{CI}$ $0.84-0.88), \quad 0.83 \quad(95 \% \quad$ CI $\quad 0.81-0.85, \quad 0.78 \quad(95 \% \quad$ CI 0.77-0.80), and 0.80 (95\% CI 0.78-0.82) for females, respectively, even after full multivariable adjustment ( $P$ trend $<0.001$, Table 3 , model 3 ). To further investigate the association between height and ESRD risk according to sex, subjects were divided into deciles according to adult height for sex, and the HR of ERSD was evaluated. All other groups had a significantly lower risk of ESRD than the lowest decile group in both males and females with type 2 DM (Supplementary Fig. 1).

\section{Subgroup analyses}

Figure 2 shows the relationship between adult height and ESRD when stratified by age, sex, social factors, and comorbidities. Subgroup analyses were performed after adjustments for age, sex, BMI, smoking, alcohol intake, regular exercise, income, hyperlipidemia, hypertension, CKD, oral hypoglycemic agent use, insulin use, and DM duration $>5$ years. The association between adult height and risk of ESRD was weaker in the 30- to 39-year-old age group than in the 40- to 64-year-old age group and the $\geq 65$-year-old age group. In addition, the association between adult height and ESRD was also weaker in heavy drinkers and underweight of $\mathrm{BMI}<18.5 \mathrm{~kg} / \mathrm{m}^{2}$ and obese patients of BMI $>30 \mathrm{~kg} / \mathrm{m}^{2}$, compared to non-drinkers and the normal to overweight group of $18.5 \leq \mathrm{BMI} \leq 30$ $\mathrm{kg} / \mathrm{m}^{2}$. In contrast, there were no significant differences in the risk of developing ESRD of diabetic patients with a short height between the subgroups of sex, regular exercise, smoking, abdominal obesity, and comorbidities. The lowest quintile of adult height remained a higher risk for ESRD in type 2 DM compared with the other quintiles,

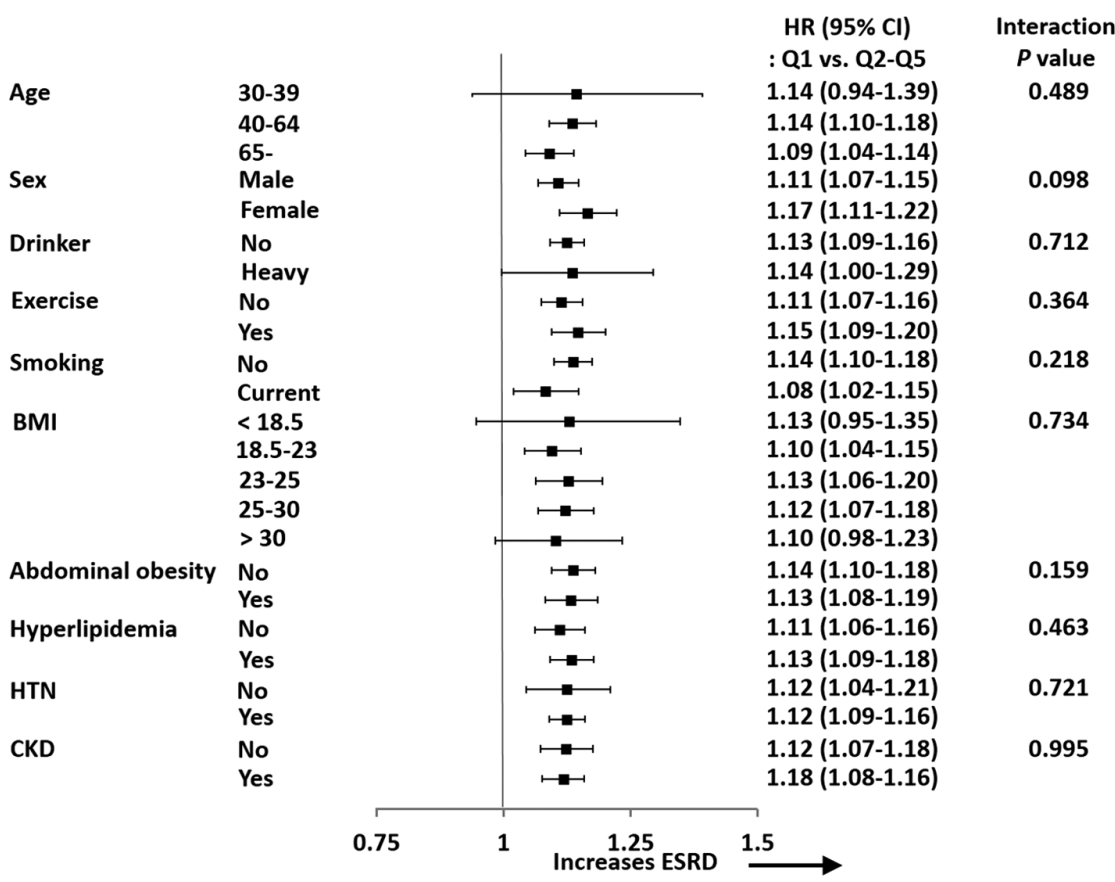

\section{Figure 2}

Hazard ratios and $95 \%$ Cls of end-stage renal disease in the lowest quintile vs higher four quintiles of adult height in subgroups of diabetic patients. https://ec.bioscientifica.com https://doi.org/10.1530/EC-20-0319 (c) 2020 The authors Published by Bioscientifica Ltd
This work is licensed under a Creative Commons Attribution-NonCommercial 4.0 International License. ded from Bioscientifica.com at 04/26/2023 10:20:00AM 
regardless of which subgroup the patients belonged to of sex, regular exercise, smoking, abdominal obesity, presence of hyperlipidemia, hypertension, and CKD.

\section{Discussion}

This study demonstrated for the first time, an inverse relationship between adult height and the incidence of ESRD in diabetic patients in a nationwide large prospective cohort. Although baseline eGFR was relatively low in taller diabetic patients compared to shorter patients, taller adults showed lower incidences of ESRD and all-cause death compared with shorter adults, even after adjustment for confounding factors. There was a significant difference in the relationship between the incidences of ESRD, all-cause death, and adult height in both males and females. These findings suggest that short adult height was a significant predictor of the incidence of ESRD and all-cause mortality in diabetic patients.

Adult height represents a balance between nutritional intake and losses, particularly during growth periods. Socioeconomic status is closely correlated with both adult height and health outcomes (17). Short height is likely to result in a low socioeconomic background, which was hypothesized to mediate the relationship between adult height and various chronic diseases. Our results showed significant associations between height and some socioeconomic indicators, such as income level and regular exercise. Unexpectedly, shorter diabetic patients had lower comorbidity of underlying disorders, such as hyperlipidemia and CKD; had a shorter duration of DM; and used less insulin and OHA. Furthermore, shorter diabetic patients were drinking less than taller diabetic patients. Nevertheless, shorter diabetic patients had significantly increased incidence of ESRD and allcause mortality, after adjustment for income level, smoking, alcohol consumption, and pre-existing medical conditions. These findings suggest that short adult height may be a more important risk factor for ESRD and mortality than social behaviors or pre-existing medical conditions in adulthood.

Adult height has an independent relationship with diabetic microvascular complications in diabetic patients. Rossing et al. demonstrated that the risk of developing diabetic nephropathy decreased $3.3 \%$ per centimeter increase in height in male patients with type $1 \mathrm{DM}$ (18). Another previous study also showed that patients with macroproteinuria were significantly shorter than patients without proteinuria in both male and female patients with type $2 \mathrm{DM}$ (12). In the large cross-sectional Finnish Diabetic Nephropathy (FinnDiane) study and the longitudinal study from the Diabetes Control and Complications Trial (DCCT), patients in the lowest quartile of adult height had increased risks of diabetic nephropathy and proliferative diabetic retinopathy, compared with other quartiles of patients with type $1 \mathrm{DM}$ (14). Insulin resistance also contributes to the microvascular complications of DM, independent of metabolic control and hypertension (19). Previous studies reported that short adult height is associated with increased risk of glucose intolerance, impaired $\beta$-cell function, and insulin resistance in diabetic patients and the general population $(8,20,21,22)$. These consistent relationships between short adult height and insulin resistance may be implicated in the pathogenesis of diabetic nephropathy, and may explain why short adult height is an independent risk factor for the incidence of ESRD caused by diabetic nephropathy.

Fewer nephrons in the kidneys is a possible explanation for the association between height and risk of ESRD. Short height is a long-term consequence of intrauterine growth retardation and catch-up failure in early childhood (23). Adult height is directly associated with birth weight (24), and low birth weight is associated with increased risk of hypertension and glucose intolerance along with decreased renal function $(23,25)$. Indeed, a previous study demonstrated that nephron number increases by 257,426 per $\mathrm{kg}$ increased birth weight (26). Nephron number is also independently correlated with adult height, and male adults have an increase of 28,000 glomeruli per centimeter increase in height $(27,28)$. The presence of fewer nephrons results in reduced glomerular filtration surface area, leading to systemic and glomerular capillary hypertension (29). Therefore, short adult height may increase the likelihood of decreasing renal function and increase BP, which may lead to increased risk of ESRD.

Other possible explanations for the association between adult height and risk of ESRD is the growth hormone/insulin-like growth factor-1 (GH/IGF-1) system. IGF-1 levels were reported to be positively associated with height $(30,31)$. The kidney is a significant source of IGF-1 synthesis, some of which is released into circulation. In addition, the kidney is a target organ of IGF-1 action. IGF-1, directly and indirectly, affects renal hemodynamics by interacting with the renin-angiotensin system, promoting nephron hypertrophy, and stimulating tubular phosphate transport $(32,33,34)$. GH and IGF-1 resistance play an additional role in the decreased growth of children with CKD and the pathogenesis of diabetic kidney disease $(35,36)$. In addition, low IGF-1 levels are 
associated with an increased risk of all-cause mortality and cardiovascular disease mortality in the general elderly population or patients with type 2 diabetes $(37,38)$. Short diabetic patients may have low IGF-1 levels, and therefore higher risk of ESRD and all-cause mortality than taller patients. Unfortunately, we did not measure growth hormone levels in this study. Therefore, further analysis may be needed to elucidate a direct association between growth hormone, adult height, and the development of end-stage renal disease in patients with type $2 \mathrm{DM}$.

The major limitations of the study include its observational design of a prospective cohort with possible unmeasured confounding factors. The biological mechanism for the relationship between adult height and the incidence of ESRD may be hard to explain. Second, the diagnosis of ESRD was assessed based on ICD-10 codes, leading to the possibility of misclassification. Finally, we did not confirm environmental factors in childhood that could affect adult height. Despite the adjustment for smoking and drinking behavior, physical exercise, and income levels in multivariate analysis, nutritional and socioeconomic status during childhood might be more associated with height than those factors during adulthood. However, our study has several significant strengths. We analyzed an entire nationwide cohort, including both males and females, as well as young and elderly people of type $2 \mathrm{DM}$. The follow-up period was long enough to confirm significant discrepancies in each ESRD event and death. We analyzed not only the incidence rates of newly diagnosed ESRD, but also demonstrated a significant difference in all-cause mortality rates.

Although adult height is mainly determined by genetic influences, nutritional environment in early life may determine adult height, and short adult height consequently increases the risk of ESRD and all-cause mortality. This study provides strong justification to continue to implement and expand the effort for nutritional improvement in childhood to restrain the poor renal outcomes and death in type 2 DM. Further investigation is needed into the possible role of epigenetic modifications in the association between short height and ESRD in type 2 DM.

\section{Supplementary materials}

This is linked to the online version of the paper at https://doi.org/10.1530/ EC-20-0319.

\section{Declaration of interest}

The authors declare that there is no conflict of interest that could be perceived as prejudicing the impartiality of the research reported.

\section{Funding}

This research was supported by a grant of the Korea Health Technology R\&D Project through the Korea Health Industry Development Institute (KHIDI), funded by the Ministry of Health \& Welfare, Republic of Korea, grant number $\mathrm{HI} 18 \mathrm{CO} 275$.

\section{References}

1 Kim KM, Oh HJ, Choi HY, Lee H \& Ryu DR. Impact of chronic kidney disease on mortality: a nationwide cohort study. Kidney Research and Clinical Practice 201938 382-390. (https://doi.org/10.23876/j. krcp.18.0128)

2 Centers for Disease Control and Prevention. Incidence of endstage renal disease among persons with diabetes - United States, 1990-2002. Morbidity and Mortality Weekly Report 200554 1097-1100. (available at: https://www.cdc.gov/mmwr/preview/mmwrhtml/ mm5443a2.htm)

3 Assogba FG, Couchoud C, Hannedouche T, Villar E, Frimat L, FagotCampagna A, Jacquelinet C, Stengel B \& French Renal Epidemiology and Information Network Registry. Trends in the epidemiology and care of diabetes mellitus-related end-stage renal disease in France, 2007-2011. Diabetologia 201457 718-728. (https://doi.org/10.1007/ s00125-014-3160-9)

4 Krolewski AS, Skupien J, Rossing P \& Warram JH. Fast renal decline to end-stage renal disease: an unrecognized feature of nephropathy in diabetes. Kidney International 201791 1300-1311. (https://doi. org/10.1016/j.kint.2016.10.046)

5 Barker DJ. The fetal and infant origins of disease. European Journal of Clinical Investigation 199525 457-463. (https://doi. org/10.1111/j.1365-2362.1995.tb01730.x)

6 Korhonen PE, Kautiainen H \& Eriksson JG. The shorter the person, the higher the blood pressure: a birth cohort study. Journal of Hypertension 201735 1170-1177. (https://doi.org/10.1097/HJH.0000000000001300)

7 Lee MY, Nam GE, Han K, Kim DH, Kim YH, Cho KH \& Park YG. Association between height and hypercholesterolemia in adults: a nationwide population-based study in Korea. Lipids in Health and Disease 201918 198. (https://doi.org/10.1186/s12944-019-1148-7)

8 Vangipurapu J, Stancakova A, Jauhiainen R, Kuusisto J \& Laakso M. Short adult stature predicts impaired beta-cell function, insulin resistance, glycemia, and type 2 diabetes in Finnish men. Journal of Clinical Endocrinology and Metabolism 2017102 443-450. (https://doi. org/10.1210/jc.2016-2933)

9 Forsen T, Eriksson J, Qiao Q, Tervahauta M, Nissinen A \& Tuomilehto J. Short stature and coronary heart disease: a 35-year follow-up of the Finnish cohorts of the seven countries study. Journal of Internal Medicine 2000248 326-332. (https://doi.org/10.1046/ j.1365-2796.2000.00747.x)

10 Schmidt M, Botker HE, Pedersen L \& Sorensen HT. Adult height and risk of ischemic heart disease, atrial fibrillation, stroke, venous thromboembolism, and premature death: a population based 36-year follow-up study. European Journal of Epidemiology 201429 111-118. (https://doi.org/10.1007/s10654-013-9867-y)

11 Xie XW, Xu L, Wang YX \& Jonas JB. Body height and ocular diseases. The Beijing eye study. Graefe's Archive for Clinical and Experimental Ophthalmology 2009247 1651-1657. (https://doi.org/10.1007/ s00417-009-1161-z)

12 Fava S, Azzopardi J, Watkins PJ \& Hattersley AT. Adult height and proteinuria in type 2 diabetes. Nephrology, Dialysis, Transplantation 200116 525-528. (https://doi.org/10.1093/ndt/16.3.525)

13 Jacobsen P, Rossing K, Tarnow L, Rossing P, Mallet C, Poirier O, Cambien F \& Parving HH. Progression of diabetic nephropathy in normotensive type 1 diabetic patients. Kidney International: Supplement 199971 S101-S105. (https://doi.org/10.1046/j.15231755.1999.07125.x) 
14 Waden J, Forsblom C, Thorn LM, Saraheimo M, RosengardBarlund M, Heikkila O, Hietala K, Ong K, Wareham N, Groop PH, et al. Adult stature and diabetes complications in patients with type 1 diabetes: the FinnDiane study and the diabetes control and complications trial. Diabetes 200958 1914-1920. (https://doi. org/10.2337/db08-1767)

15 Song SO, Jung CH, Song YD, Park CY, Kwon HS, Cha BS, Park JY, Lee KU, Ko KS \& Lee BW. Background and data configuration process of a nationwide population-based study using the Korean National Health Insurance System. Diabetes and Metabolism Journal 201438 395-403. (https://doi.org/10.4093/dmj.2014.38.5.395)

16 Lee YH, Han K, Ko SH, Ko KS, Lee KU \& Taskforce Team of Diabetes Fact Sheet of the Korean Diabetes Association. Data analytic process of a nationwide population-based study using National Health Information Database established by National Health Insurance Service. Diabetes and Metabolism Journal 201640 79-82. (https://doi. org/10.4093/dmj.2016.40.1.79)

17 Perkins JM, Subramanian SV, Davey Smith G \& Ozaltin E. Adult height, nutrition, and population health. Nutrition Reviews $2016 \mathbf{7 4}$ 149-165. (https://doi.org/10.1093/nutrit/nuv105)

18 Rossing P, Tarnow L, Nielsen FS, Boelskifte S, Brenner BM \& Parving HH. Short stature and diabetic nephropathy. BMJ 1995310 296-297. (https://doi.org/10.1136/bmj.310.6975.296)

19 Groop PH, Forsblom C \& Thomas MC. Mechanisms of disease: pathway-selective insulin resistance and microvascular complications of diabetes. Nature Clinical Practice: Endocrinology and Metabolism 20051 100-110. (https://doi.org/10.1038/ncpendmet0046)

20 Brown DC, Byrne CD, Clark PM, Cox BD, Day NE, Hales CN, Shackleton JR, Wang TW \& Williams DR. Height and glucose tolerance in adult subjects. Diabetologia 199134 531-533. (https:// doi.org/10.1007/BF00403292)

21 Guerrero-Igea FJ, Lepe-Jimenez JA, Garrido-Serrano A \& PalomoGil S. Association among hyperinsulinemia, family history of diabetes, and diminutive stature in normoglycemic premenopausal women. Diabetes Care 200124 602-603. (https://doi.org/10.2337/ diacare.24.3.602-a)

22 Leger J, Levy-Marchal C, Bloch J, Pinet A, Chevenne D, Porquet D, Collin D \& Czernichow P. Reduced final height and indications for insulin resistance in 20 year olds born small for gestational age: regional cohort study. BMJ 1997315 341-347. (https://doi. org/10.1136/bmj.315.7104.341)

23 Luyckx VA, Bertram JF, Brenner BM, Fall C, Hoy WE, Ozanne SE \& Vikse BE. Effect of fetal and child health on kidney development and long-term risk of hypertension and kidney disease. Lancet 2013382 273-283. (https://doi.org/10.1016/S0140-6736(13)60311-6)

24 Sørensen HT, Sabroe S, Rothman KJ, Gillman M, Steffensen FH, Fischer P \& Sørensen TI. Birth weight and length as predictors for adult height. American Journal of Epidemiology 1999149 726-729. (https://doi.org/10.1093/oxfordjournals.aje.a009881)

25 Hofman PL, Cutfield WS, Robinson EM, Bergman RN, Menon RK, Sperling MA \& Gluckman PD. Insulin resistance in short children with intrauterine growth retardation. Journal of Clinical Endocrinology and Metabolism 199782 402-406. (https://doi.org/10.1210/ jcem.82.2.3752)
26 Hughson M, Farris 3rd AB, Douglas-Denton R, Hoy WE \& Bertram JF. Glomerular number and size in autopsy kidneys: the relationship to birth weight. Kidney International 200363 2113-2122. (https://doi. org/10.1046/j.1523-1755.2003.00018.x)

27 Hoy WE, Hughson MD, Bertram JF, Douglas-Denton R \& Amann K. Nephron number, hypertension, renal disease, and renal failure. Journal of the American Society of Nephrology 200516 2557-2564. (https://doi.org/10.1681/ASN.2005020172)

28 Hoy WE, Hughson MD, Singh GR, Douglas-Denton R \& Bertram JF. Reduced nephron number and glomerulomegaly in Australian Aborigines: a group at high risk for renal disease and hypertension. Kidney International 200670 104-110. (https://doi.org/10.1038/ sj.ki.5000397)

29 Denic A, Mathew J, Lerman LO, Lieske JC, Larson JJ, Alexander MP, Poggio E, Glassock RJ \& Rule AD. Single-nephron glomerular filtration rate in healthy adults. New England Journal of Medicine 2017 376 2349-2357. (https://doi.org/10.1056/NEJMoa1614329)

30 Ben-Shlomo Y, Holly J, McCarthy A, Savage P, Davies D, Gunnell D \& Davey Smith G. An investigation of fetal, postnatal and childhood growth with insulin-like growth factor I and binding protein 3 in adulthood. Clinical Endocrinology 200359 366-373. (https://doi. org/10.1046/j.1365-2265.2003.01857.x)

31 Rosenfeld RG. Insulin-like growth factors and the basis of growth. New England Journal of Medicine 2003349 2184-2186. (https://doi org/10.1056/NEJMp038156)

32 Kobayashi S, Moriya H, Nakabayashi I, Nishiyama J \& Fukuda T. Angiotensin II and IGF-I may interact to regulate tubulointerstitial cell kinetics and phenotypic changes in hypertensive rats. Hypertension Research 200225 257-269. (https://doi.org/10.1291/hypres.25.257)

33 Marsh AC, Gibson KJ, Wu J, Owens PC, Owens JA \& Lumbers ER. Insulin-like growth factor I alters renal function and stimulates renin secretion in late gestation fetal sheep. Journal of Physiology $20015 \mathbf{5 3 0}$ 253-262. (https://doi.org/10.1111/j.1469-7793.2001.02531.x)

34 Thrailkill KM. Insulin-like growth factor-I in diabetes mellitus: its physiology, metabolic effects, and potential clinical utility. Diabetes Technology and Therapeutics 20002 69-80. (https://doi. org/10.1089/152091599316775)

35 Mak RH, Cheung WW \& Roberts Jr CT. The growth hormoneinsulin-like growth factor-I axis in chronic kidney disease. Growth Hormone and IGF Research 200818 17-25. (https://doi.org/10.1016/j. ghir.2007.07.009)

36 Kamenicky P, Mazziotti G, Lombes M, Giustina A \& Chanson P. Growth hormone, insulin-like growth factor-1, and the kidney: pathophysiological and clinical implications. Endocrine Reviews 2014 35 234-281. (https://doi.org/10.1210/er.2013-1071)

37 van Bunderen CC, van Nieuwpoort IC, van Schoor NM, Deeg DJ, Lips P \& Drent ML. The association of serum insulin-like growth factor-I with mortality, cardiovascular disease, and cancer in the elderly: a population-based study. Journal of Clinical Endocrinology and Metabolism 201095 4616-4624. (https://doi.org/10.1210/jc.2010-0940)

38 Miyake H, Kanazawa I \& Sugimoto T. Decreased serum insulin-like growth factor-I level is associated with the increased mortality in type 2 diabetes mellitus. Endocrine Journal 201663 811-818. (https:// doi.org/10.1507/endocrj.EJ16-0076)

Received in final form 9 July 2020

Accepted 2 September 2020

Accepted Manuscript published online 3 September 2020 https://ec.bioscientifica.com https://doi.org/10.1530/EC-20-0319 (c) 2020 The authors Published by Bioscientifica Ltd

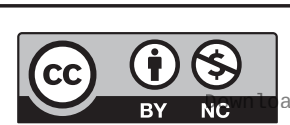

This work is licensed under a Creative Commons Attribution-NonCommercial 4.0 International License. ded from Bioscientifica.com at 04/26/2023 10:20:00AM 